\title{
52 Years of Lassa Fever Outbreaks in Nigeria, 1969-2020: An Epidemiologic Analysis of the Temporal and Spatial Trends
}

\author{
Dennis E. Agbonlahor, ${ }^{1}$ George O. Akpede, ${ }^{2 *}$ Christian T. Happi, ${ }^{3}$ and Oyewale Tomori ${ }^{4}$ \\ ${ }^{1}$ Department of Medical Laboratory Science, College of Medical Sciences, Edo State University, Uzairue, Edo State, Nigeria and Lahor Research \\ Laboratories and Medical Centre, Benin City, Edo State, Nigeria; ${ }^{2}$ Department of Paediatrics, College of Medicine, Ambrose Alli University, Ekpoma, \\ Edo State, Nigeria and Institute of Lassa Fever Research and Control, Irrua Specialist Teaching Hospital, Irrua, Edo State, Nigeria; ${ }^{3}$ Department of \\ Biological Sciences, Redeemer's University, Ogun State, Nigeria and African Center of Excellence for Genomics of Infectious Diseases, Redeemer's \\ University, Ogun State, Nigeria; ${ }^{4}$ Redeemer's University, Ede, Osun State, Nigeria and National Laboratory Technical Working Group, Federal Ministry \\ of Health, Abuja, Nigeria
}

\begin{abstract}
The year 2020 made 52 years since the first report of Lassa fever (LF) outbreaks from Nigeria, but what progress has been made in its control? We sought to answer this through an epidemiologic analysis of the temporal and spatial trends of the outbreaks from 1969 to 2020. The analysis showed an overall strengthening of the outbreaks, hallmarked by the change from irregular to regular annual and from limited local to nationwide outbreaks, while there was a sharp contrast between the upward trend in case numbers and downward trend in case fatality. Pending the availability of effective vaccines, greater effort is required to reverse the upward trend in case numbers and sustain the downward trend in case fatality. We discuss the factors associated with the observed trends as well as the prerequisites for further improvements.
\end{abstract}

\section{INTRODUCTION}

Lassa fever (LF) is a severe viral hemorrhagic disease that was first reported in 1969 in an American Missionary Nurse who worked in Lassa town in Borno State of Nigeria. It includes a spectrum of illness, ranging from mild to a very severe and often fatal. The disease was first described clinically by several authors in 1970, ${ }^{1-3}$ while the etiologic agent was first characterized by Buckley and Casals, ${ }^{4}$ also in 1970. Nigeria has since 1969 , recorded repeated outbreaks of the disease. ${ }^{5}$

The etiologic agent, Lassa virus (LASV), belongs to the family Arenaviridae, and is transmitted to humans mainly by a multimamate rat belonging to the Mastomys species complex, which also serves as the zoonotic reservoir of the virus. ${ }^{6,7}$ Mastomys spp. are peri-domestic rodents that live in and around human settlements. They show no clinical symptoms but are believed to be lifelong carriers of the virus, which they shed through their urine, feces, and respiratory secretions. ${ }^{6-9}$ Rodent-to-human transmission also occurs through contact with the blood and tissues of infected rodents. ${ }^{6,10}$ Besides rodent-to-human transmission of infection, nosocomial epidemics frequently occur in hospital settings with poor infection prevention and control (IPC) practices. ${ }^{11}$ Lassa virus may be isolated from the tissues, blood, urine, semen, and other body fluids of infected humans who may continue to secret the virus for 30 days or more following recovery..$^{11,12}$

The incubation period is about 10 days on the average but ranges between 1 and 21 days. ${ }^{12}$ About $80 \%$ of infected persons are asymptomatic or show only mild symptoms, while the remaining $20 \%$ have severe illness that could include multiorgan dysfunction. ${ }^{10,13-17}$ Death is the outcome in $15-20 \%$ of severely ill hospitalized cases, ${ }^{14,16}$ but case fatalities as high as $50-70 \%$ have been reported during outbreaks. ${ }^{5,17}$ Bilateral or unilateral sensory-neural deafness is frequent among survivors ${ }^{18,19}$ and has been reported in

*Address correspondence to George O. Akpede, Department of Paediatrics, College of Medicine, Ambrose Alli University, P.M.B. 14, Ekpoma, Edo State, Nigeria. E-mail: georgeakpede@yahoo.co. uk about $33.2 \%$ (range $4-75 \%){ }^{20}$ Lassa fever in pregnancy is particularly severe, with spontaneous abortion and high fatality rates during the third trimester. ${ }^{21-24}$ Lassa fever in children appears to be less frequent than in adults, but is associated with the same spectrum of illness albeit with a generally lower case fatality, except in young children. ${ }^{22,25-27}$ The public health and medical importance of LF in Nigeria is illustrated in Table 1 with data on its contribution to febrile illnesses, ${ }^{26,28,29}$ and maternal mortality. ${ }^{23,24}$ These are aside from its socioeconomic consequences, ${ }^{13,20}$ and contribution to the loss of healthcare workers. ${ }^{30}$

The 50th anniversary of the first report of LF was marked with an international conference in January $2019,{ }^{31}$ but what progress has been made in its control in Nigeria? We sought to answer this question through a review of the trend of the outbreaks over the 52 years, 1969-2020, as hallmarked by the trends in annual numbers of cases and deaths, and spatial distribution. We then discussed the associated factors, including the national response to the outbreaks, and conclude with recommendations on the way forward.

\section{METHODS}

Data on the number of cases and deaths from LF in Nigeria for each year from 1969 to 2020 were retrieved from publications obtained using Medline Entrez-PubMed and Google search. These were supplemented with data from Irrua Specialist Teaching Hospital (ISTH), Irrua, Nigeria, and the weekly situation reports of the Nigeria Center for Disease Control (NCDC). The terms suspected, confirmed, and epidemiologically confirmed cases were used as defined by the US Centers for Disease Control and Prevention ${ }^{32}$ and the WHO. ${ }^{33}$

We classified the outbreaks over the 52 years into phases based on the geographical parts of the country involved, and the annual regularity of the outbreaks. Phase I thus included the period with irregular outbreaks in either the northern or southern parts of the country, whereas there were regular outbreaks in both parts in phase III.

For ease of analysis, we subdivided the 52 years into 13 periods of 4 years each. Frequencies and proportions were 
TABLE 1

Indices of the public health and medical burdens of Lassa fever in Nigeria, 1969-2020

\begin{tabular}{ll}
\hline \multicolumn{1}{c}{ Index } & \multicolumn{1}{c}{ Rates $^{-}$} \\
\hline Prevalence of LF in selected populations of hospital patients & $6 \%$ of febrile adults ${ }^{29}$ \\
& $3.5 \%$ of febrile children \\
& $0.6 \%$ of antenatal admissions ${ }^{23}$ \\
& $0.3 \%$ of Labor Ward admissions ${ }^{23}$ \\
No. of affected states/total number of states plus FCT $\left(N=37^{*}\right)$ by 2020 & $36 / 37 \dagger(97.3 \%)$ \\
No. of years with a reported outbreak/total number of years since 1969 & $33 / 52(63.5 \%)$ \\
Case fatality among hospitalized patients with LF & $41 \%$ from 1969-1986 $; 24-31 \%$ from 2009-2018 \\
Contribution to maternal mortality & $13 \%$ \\
\hline
\end{tabular}

FCT $=$ Federal Capital Territory

Total number of states $=36 ; 35 / 36(97.2 \%)$ states have reported at least one outbreak

† Only Bayelsa State did not report an outbreak during the 52 years covered by this report.

compared between years or periods, as the case may be, with $\mathrm{n} \times \mathrm{n} \chi^{2}$ using Open Epi (http://www.openepi.com), and $P$ values $<0.05$ were accepted as significant. We also used extended Mantel-Haenszel $\chi^{2}$ for linear trend to determine the significance of the trends observed. The results are presented as overall and disaggregated based on outbreak years and periods, and as Odds Ratios $(95 \% \mathrm{Cl})(\mathrm{OR}[95 \% \mathrm{Cl}])$ of the differences between proportions.

\section{RESULTS}

Chronology and spatiality of LF Outbreaks in Nigeria, 1969-2020. Outbreaks were reported in 33 (63.4\%) of the 52 years from 1969 to 2020 . There were no reported outbreaks between 1981 and 1988, but from 1998 there was no year without an outbreak. The chronology of outbreaks is shown in Table 2, in terms of the number of affected states and geopolitical zones at 4-yearly intervals, and illustrated in Figure 1 in terms of the trend in numbers and proportions of affected states. The trend was highly significant $(P<0.001)$.

The overall spatial distribution of outbreaks from 1969 to 2020 is illustrated in Figures 2 and 3, which highlights both the differences between the geopolitical zones and differences between the states in terms of differences in the number of outbreak years (NOOYs). The order of magnitude of the average NOOYs among the geopolitical zones, derived as the sum of NOOYs of individual states within the zone divided by the number of states in that zone, was North Central (11.0 years) $>$ Northeast $(9.2$ years) $>$ Southeast $(8.0$ years $)>$
South-South $(7.5$ years $)>$ Southwest $(6.8$ years $)>$ Northwest (5.4 years). Among the states, Edo State in the South-South had the highest NOOYs (23 years or $69.7 \%$ of the 33 national outbreak years) followed by Plateau State (18 years, $54.5 \%$ ) in the North Central (Figure 2). There was no significant difference between Edo and Plateau States in the NOOYs $P=307$ ), but the NOOYs in Edo State was significantly higher than that of the states with the highest NOOYs in the other geopolitical zones (12 years or $36.4 \%$ in each of Bauchi and Taraba States in the Northeast, Kaduna State in the Northwest, Ebonyi State in the Southeast; $P=0.012$ and 13 years, $39.4 \%$ in Ondo State in the Southwest; $P=0.024)$. There were no significant differences between Plateau and the other states $(P=0.208$ for Plateau versus Bauchi, taraba and Ebonyi and $P=0.317$ for Plateau versus Ondo).

There was a surge in the number of affected states and geopolitical zones at about the close of the fourth decade, or from the 10th 4-year period (2005-2008), which continued to 2020. In 2016, in particular, the year with the most widespread outbreaks before the further surge in 2020,28 states or $78 \%$ of the 36 states in the country were affected. By 2020, only 1 (2.7\%) of the 37 States $(N=36)$ plus Federal Capital Territory $(N=1)$ had not had a reported case of LF; this was Bayelsa State in the South-South Zone (Figure 3 and Supplemental Table 1).

The chronology of severity of the outbreaks in terms of the number of suspected cases, the crude average prevalence of both suspected and unsuspected cases per million of the population, and case fatality among suspected cases are

TABLE 2

No. and geopolitical disposition of states with Lassa fever outbreaks, 1969-2020

\begin{tabular}{lcccc}
\hline Study period & $\begin{array}{c}\text { No. of years with an outbreak/ } \\
\text { outbreak-free years, if any }\end{array}$ & $\begin{array}{c}\text { No. (\%) of states with an outbreak } \\
(N=36)^{\star}\end{array}$ & $\begin{array}{c}\text { No. (\%) of geopolitical zones with } \\
\text { an outbreak }(N=6) \dagger\end{array}$ & $\begin{array}{c}\text { Geopolitical disposition of states } \\
\text { with an outbreak }\end{array}$ \\
\hline $1969-1972$ & $3 / 1972$ & $4(11.1)$ & $2(33.3)$ & NC, NE \\
$1973-1978$ & $2 / 1973,1976$ & $3(8.3)$ & $2(33.3)$ & NC, SE \\
$1977-1980$ & $1 / 1977-79$ & $1(2.8)$ & $1(16.7)$ & NC \\
$1981-1984$ & 0 & 0 & 0 & NA \\
$1985-1988$ & 0 & 0 & $2(33.3)$ & NA \\
$1989-1992$ & $1(1990-92)$ & $2(5.6)$ & $2(33.3)$ & SE, SS \\
$1993-1996$ & $3(1996)$ & $10(27.8)$ & $2(33.3)$ & SE, SS \\
$1997-2000$ & $3(1997)$ & $5(13.9)$ & $2(33.3)$ & NC, SW \\
$2001-2004$ & 4 & $5(13.9)$ & $4(66.7)$ & SS, SW \\
$2005-2008$ & 4 & $9(25.0)$ & $6(100.0)$ & SC, SE, SW, SS \\
$2009-2012$ & 4 & $22(61.1)$ & $6(100.0)$ & All 6 + FCT \\
$2013-2016$ & 4 & $28(77.8)$ & $6(100.0)$ & All 6 + FCT \\
$2017-2020$ & 4 & $35(97.2)$ & All 6 + FCT \\
\hline
\end{tabular}

FCT = Federal Capital Territory; NA = not applicable; NC = North Central Geopolitical Zone (Benue, Plateau, Nasarawa, Kogi, Niger States); NE = North East Geopolitical Zone (Borno, Yobe, Adamawa, Taraba, Bauchi, and Gombe States); NW = North West Geopolitical Zone (Kaduna, Katsina, Kebi, Zamfara, Sokoto, Kwara and Kano States); SE = South East Geopolitical Zone (Enugu, Anambra, Ebonyi, Imo, and Abia States); SS = South-South Geopolitical Zone (Bayelsa, Delta, Rivers, Cross River, Edo, and Akwa lbom States); SW = South West Geopolitical Zone (Lagos, Ogun, Oyo, Ondo, Ekiti, and Osun States). Statistics: Extended Mantel-Haenszel $\chi^{2}$ for linear trend $/ P$ are: ${ }^{*} 147.63 /<0.001 ; \uparrow 23.1 /<0.001$. 


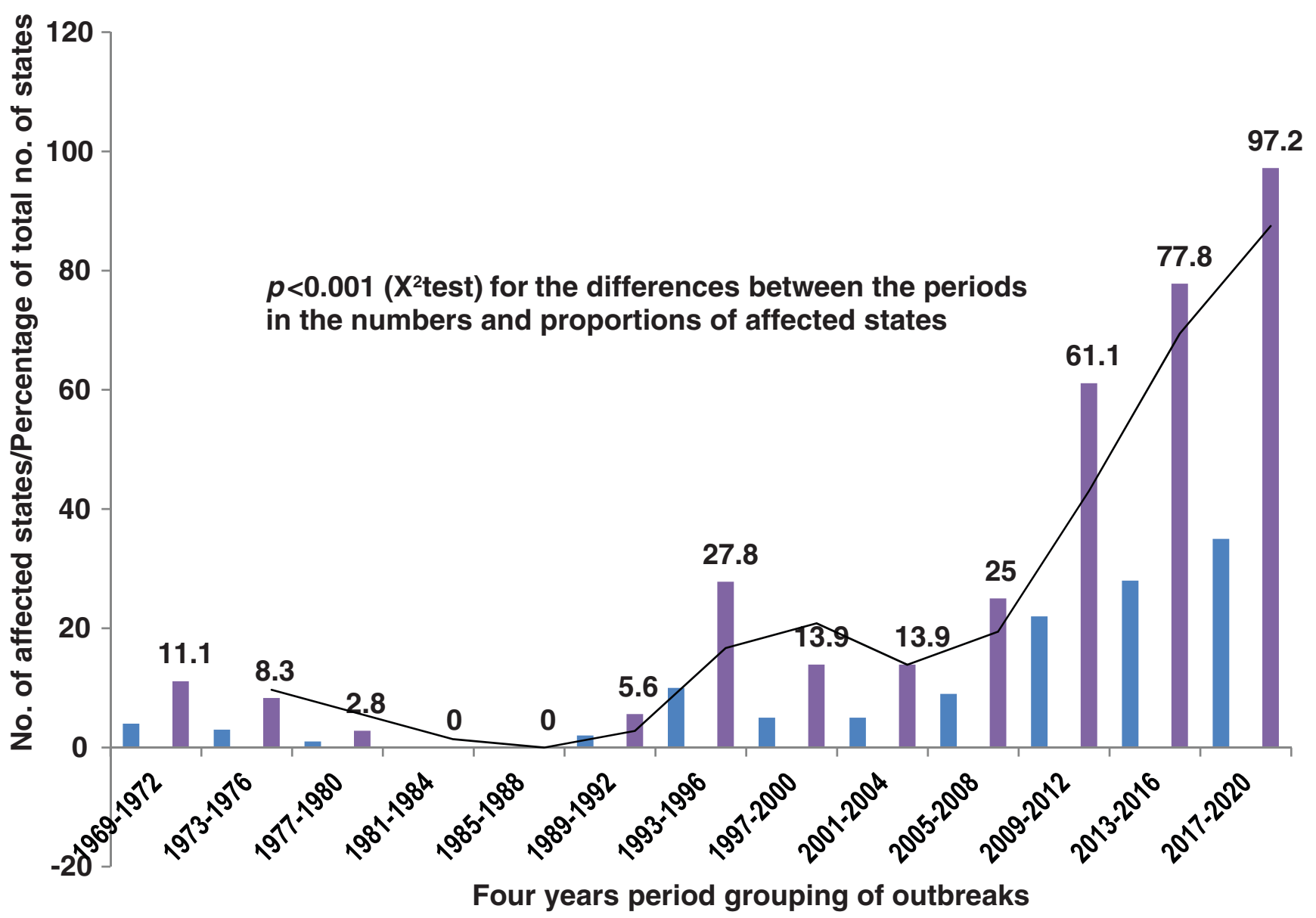

No. of affected states

No. of states as \% of total no. of States $(\mathrm{N}=36)$

\section{- 2 per. Mov. Avg. (No. of states as \% of total no. of States $(\mathrm{N}=36)$ )}

FIGURE 1. Trend in numbers and proportions of affected states during Lassa fever outbreaks in Nigeria, 1969-2020 (2 per. Mov. Avg. = 2 per moving averages). This figure appears in color at www.aitmh.org.

shown in Table 3, and illustrated in Figures 4 and 5. The sustained surge in number of cases and crude population prevalence from the 10th 4-year period onward is obvious (Figure 4). The difference between the crude average population prevalence of cases of suspected LF in 2005-2020 versus 1969-2004 $(27,440 / 170,624,657.5$ or $160.821 /$ million versus $571 / 89,577,425.07$ or 6.374 per million; OR $(95 \% \mathrm{Cl})=25.23(23.23,27.41), P<0.001)$ was highly significant.

The trend in case fatality among suspected cases was also highly significant $(P<0.001)$ as shown in Table 3 and illustrated in Figure 5. However, in contrast with the trend in the number of suspected cases, the average case fatality was markedly lower in 2005-2020 versus 1969-2004 (average case fatality of $1,656 / 27,440$ or $6.0 \%$ versus $188 / 571,32.9 \%$; OR $(95 \% \mathrm{Cl})$ of death in 2005-2020 $=0.13(0.11,0.16), P<0.001)$.

Phases of LF outbreaks in Nigeria, 1969-2020. Chronologically, we could uniquely divide the outbreaks into two distinct phases, I and III, and a two-part transition phase, IIA and $B$, based on the characteristics described in Table 4, which also highlights the differences in spatiality, caseload, and case fatality between the three phases. Phase I had irregular outbreaks, which shifted between the northern and southern parts of the country, and involved an average of 1.6 states per outbreak. Details of some of the outbreaks during this phase, some of which were hospital-based epidemics or nosocomial outbreaks, are available in previous reports. $^{1-3,11,34-37}$ However, there is a rather unique and pathetic detail from the 1989 outbreak at Ihumudum Quarters, Ekpoma, Edo State in the South-South geopolitical, which has not been described previously. We describe it here as it also vividly illustrates the potential for transmission between family members.

The Ihumudumun outbreak involved six cases in one family, the mother, father, two sons, a 6-year-old child, and one other person. The mother and 6-year old died on January 13 and 15, respectively, and the father on January 28 , about 2 weeks after the death of the wife. One of the sons of the family, FO, a 


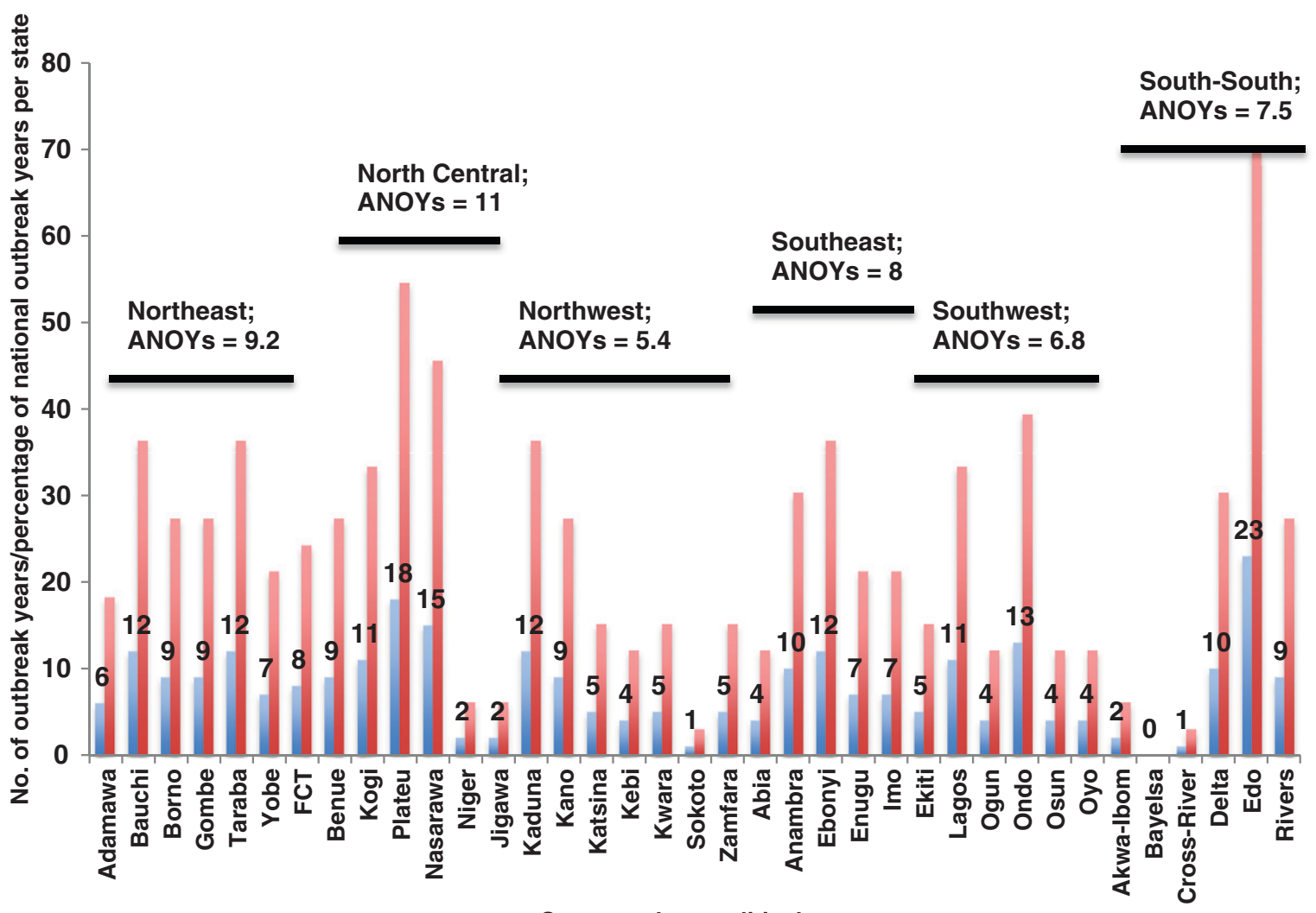

States and geopolitical zones

\section{No. of outbreak years per state \\ No. of outbreak years per state as a percentage of the total number of outbreak years nationally ( $\mathrm{N}=33$ years)}

FIGURE 2. Number of outbreak years and number of outbreak years per state as a proportion of the total number of national outbreak years of Lassa fever in Nigeria, 1969-2020 (ANOYs = average number of outbreak years). This figure appears in color at www.ajtmh.org.

medical doctor who had treated the mother at home died on February 18 following a severe febrile illness. The other son (GO), a classmate to one of us (D. E. A), who had traveled from the United States for the mother's burial, returned to the United States on January 31, 1989, and took ill by February 3 with severe fever, sore throat, and myalgia. He died on February 16, and the diagnosis of LF was confirmed post mortem. ${ }^{36}$ Ultimately, the death toll in the family was $5 / 6$ or $83 \%$, and the series of the unexplained deaths led to a tense atmosphere and rumors that "the gods of Ihumudumu had descended upon the people, visiting the sins of ancestors upon their children." This was the position until the Authorities of the United States of America notified the Nigerian Federal Ministry of Health who in turn informed one of us, O. T., that GO died of LF, which he contracted in all likelihood at Ekpoma, Nigeria. Two of us, O. T. and D. E. A., subsequently investigated the several contacts of the family in Ekpoma and found that sera from three $(7.7 \%)$ out of the 39 that could be traced had LF-specific IgM antibodies; all three were however asymptomatic (Tomori and Agbonlahor, unpublished data). The investigation was carried out amid high levels of fear, suspicion, and rumors.

The first part of the transition phase, IIA, composed of irregular annual outbreaks involving both northern and southern geopolitical zones, whereas the second part (IIB) composed of regular annual outbreaks that predominantly affected states in the southern parts of the country (Table 4). An average of 3.3 states per outbreak were involved in Phase IIA, and 1.9 states in IIB. ${ }^{37}$ There were annual outbreaks in Edo State (South-South zone) from 2000 to-2008. The other states affected during this period were in the Southwest and Southeast zones while the North Central zone was the only geopolitical zone in the north with outbreaks in 2000 and 2007 (Table 4). ${ }^{16,33,37-40}$

Phase III involved the occurrence of regular annual national outbreaks, and a surge in the number of affected states. At least about a fifth (20\%) of the 36 states in the country and at least four of the six geopolitical zones in both northern and southern parts of the country were affected annually (Table 4). There have been outbreaks in an average of $19.8(55.0 \%)$ of the 36 states, whereas the number of states affected per annum ranged from 9 (25.0\%) in 2009 through $28(77.8 \%)$ in 2016 to 35 (97.2\%) in 2020 (Table 4, Supplemental Table 1).

The phases of the outbreaks also demonstrated the contrast between the trends in caseload and case fatality. The ratios of number of clinically suspected cases were 1:10.0:269.1 in Phase I versus II versus III, whereas the ratios of case fatality were 10.2:6.4:1. These trends were significant $(P<0.001$ in both instances) as shown in Table 5 and Figure 6. 


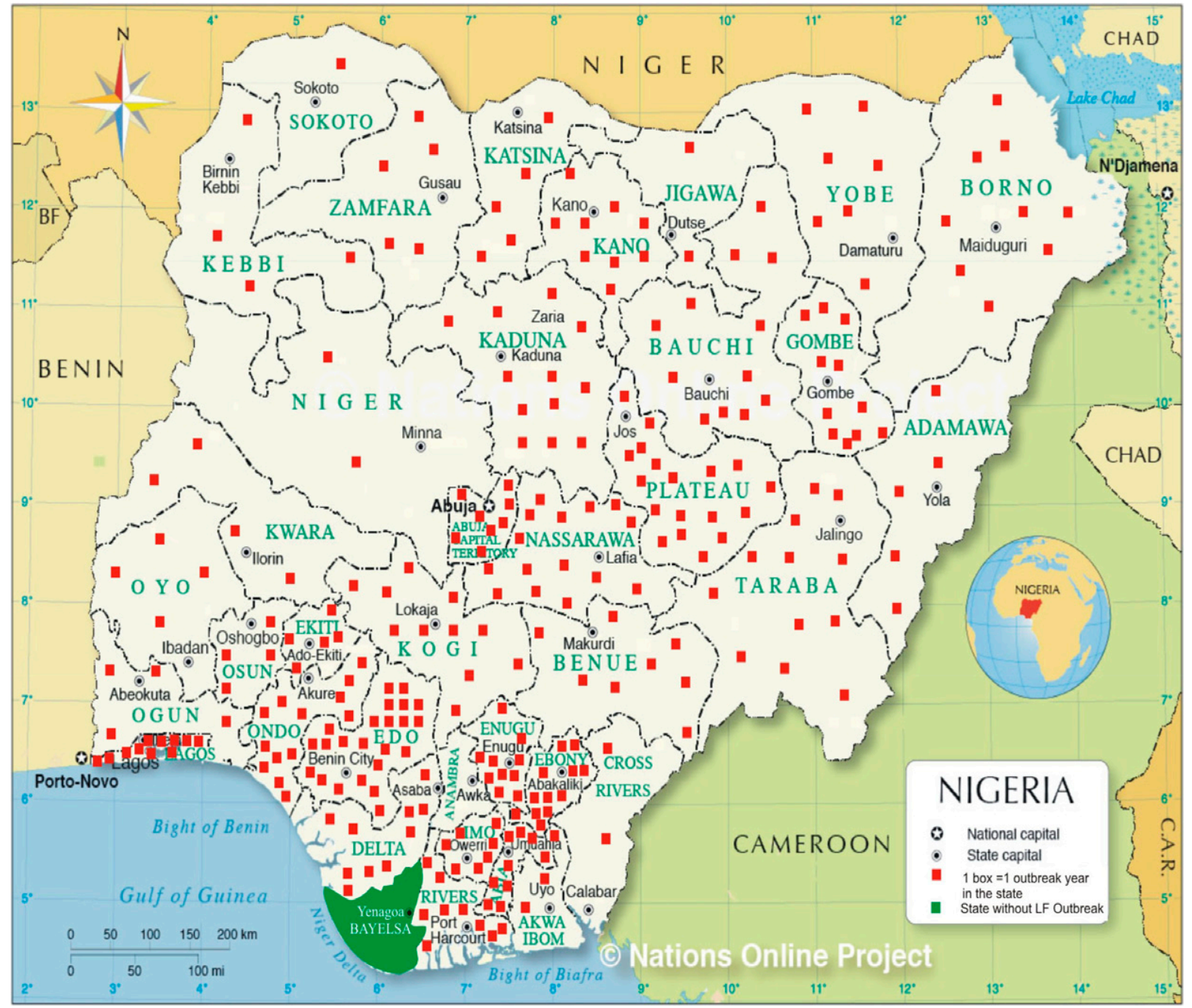

FIGURE 3. Overall burden of Lassa fever outbreaks per state in Nigeria, 1969-2020. This figure appears in color at www.ajtmh.org.

\section{DISCUSSION}

We have highlighted the growth of LF outbreaks in Nigeria, and the contrast between the trends in number of cases and case fatality. We have also more clearly defined the reality of hyperendemic zones in the country, and perhaps for the first time defined phases of the outbreaks. This is perhaps the first overview of LF outbreaks in Nigeria with a focus on the long term, and the findings are of relevance to the further development and implementation of policies aimed at mitigating

TABLE 3

Case load and case fatality of Lassa fever outbreaks in Nigeria, 1969-2020

\begin{tabular}{lccrr}
\hline \multicolumn{1}{c}{ Study period } & Average population & $\begin{array}{c}\text { No. of clinically suspected cases } \\
\text { (No. per 1 million population)* }\end{array}$ & $\begin{array}{c}\text { No. of confirmed cases (No. per 1 } \\
\text { million population)t }\end{array}$ & $\begin{array}{c}\text { No. (\%) of deaths among } \\
\text { suspected casesł }\end{array}$ \\
\hline $1969-1972$ & $56,665,493.50$ & $54(0.953)$ & $23(0.406)$ & $25(46.3)$ \\
$1973-1976$ & $62,596,869.50$ & $7(0.112)$ & $7(0.112)$ & $2(28.6)$ \\
$1977-1980$ & $70,314,952.25$ & $1(0.014)$ & $1(0.014)$ & $1(100.0)$ \\
$1981-1984$ & $78,432,910.75$ & 0 & 0 & 0 \\
$1985-1988$ & $86,943,121.75$ & 0 & 0 & 0 \\
$1989-1992$ & $96,457,454.75$ & $38(0.394)$ & $23(0.239)$ & $27(71.1)$ \\
$1993-1996$ & $106,652,895.50$ & $159(1.491)$ & $2(0.019)$ & $21(13.2)$ \\
$1997-2000$ & $117,830,333.80$ & $135(1.146)$ & $26(0.221)$ & $26(19.3)$ \\
$2001-2004$ & $130,302,793.80$ & $175(1.343)$ & $73(0.560)$ & $86(49.1)$ \\
$2005-2008$ & $144,503,231.00$ & $534(3.695)$ & $202(1.398)$ & $213(40.0)$ \\
$2009-2012$ & $160,715,500.30$ & $4,925(30.644)$ & $467(2.906)$ & $307(6.2)$ \\
$2013-2016$ & $178,817,109.80$ & $4,721(26.401)$ & $437(2.444)$ & $309(6.6)$ \\
$2017-2020$ & $198,462,788.80$ & $17,262(86.979)$ & $2,893(14.577)$ & $827(4.8)$ \\
TOTAL (1969-2020) & $114,515,035.40$ & $28,011(244.605)$ & $4,154(36.275)$ & $1,844(6.6)$ \\
\hline
\end{tabular}

Statistics I: $\chi^{2} /$ degrees of freedom/Pare: ${ }^{*} 66,570 / 12 /<0.001 ; \dagger 11940 / 12 /<0.001 ; \ddagger 2,023 / 8$ (with the first five rows merged) $/<0.001$. Statistics II: Extended Mantel-Haenszel $\chi^{2}$ for lineartrend/Pare: * $33,189.06 /<0.001 ; \dagger 4420 /<0.001 ; \ddagger 835.3 /<0.001$. 


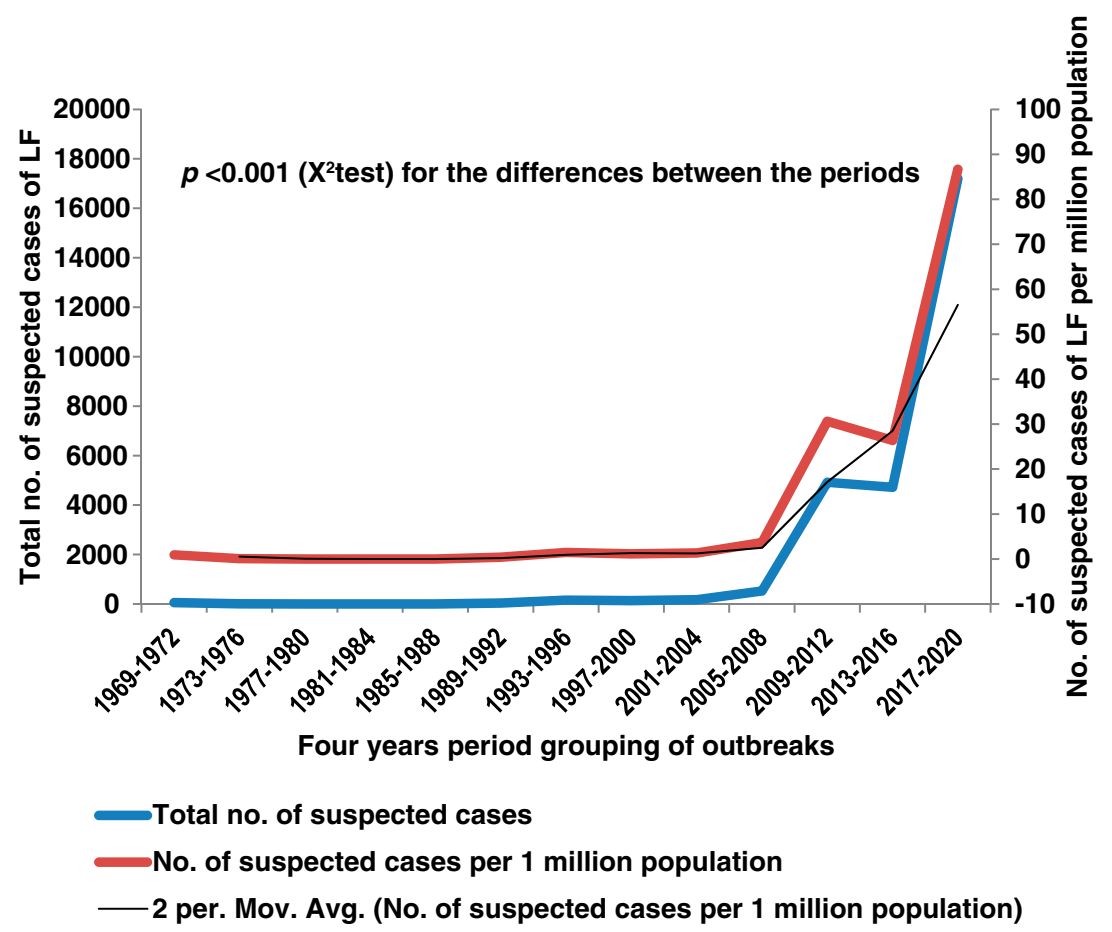

FiguRE 4. Trend in numbers of clinically suspected cases of Lassa fever in Nigeria, 1969-2020 (2 per. Mov. Avg. = 2 per moving averages). This figure appears in color at www.ajtmh.org.

and/or suppressing the longstanding epidemic. In discussing the findings, which are a cause for concern but also a reason for hope, we seek answers to three critical but interrelated questions: What factors might be responsible for strengthening the epidemic; How has the country responded; and What might be the way forward in further mitigating or suppressing the outbreaks?

Unfavorable course of LF outbreaks in Nigeria. Several interrelated factors might be at play. ${ }^{5}$ First are the difficulties in the diagnosis. The signs and symptoms of LF, especially during the early stages, readily mimic those of other endemic diseases such as malaria, typhoid, and yellow fever. ${ }^{41}$ This underscores the need for a high clinical index of suspicion in diagnosis, ${ }^{42}$ but this is oftentimes lacking. ${ }^{42,43}$ This is compounded by the lack of point-of-care diagnostic tests ${ }^{44}$ and general dearth of laboratory facilities for confirmation of diagnosis. ${ }^{45}$ The confirmation of diagnosis is imperative in the care of the individual patient, and institution of public health measures to prevent further transmission.

The laboratory diagnosis of LF relies on the detection of virus antigen, or virus-specific antibodies in blood and other body fluids. Raabe and Koehler, ${ }^{46}$ Emperador et al., ${ }^{32}$ Takah

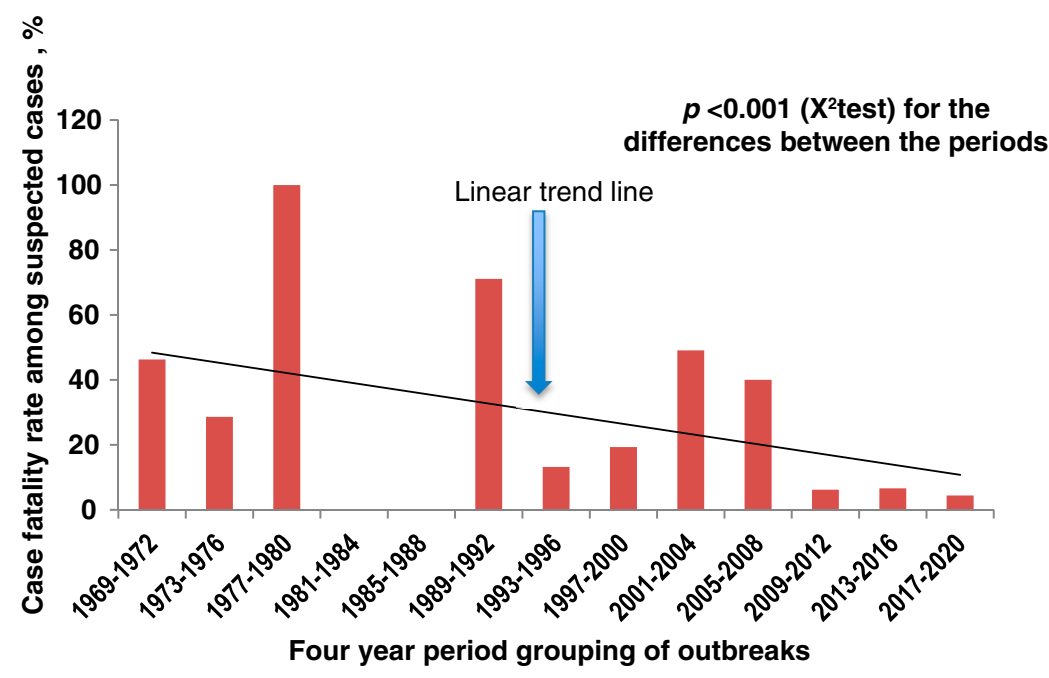

- Case fatality rate (\%) among suspected cases

FIGURE 5. Trend in case fatality among clinically suspected cases of Lassa fever in Nigeria, 1969-2020. This figure appears in color at www.ajtmh. org. 
TABLE 4

Affected geopolitical zones, and caseload and case fatality of Lassa fever by proposed phases of Lassa fever outbreaks in Nigeria, 1969-2020

\begin{tabular}{|c|c|c|c|c|c|}
\hline Phase $^{*}$ & Outbreak period & Outbreak years (affected geopolitical zones) & $\begin{array}{l}\text { Average (range) no. of } \\
\text { states affected per } \\
\text { outbreak yeart }\end{array}$ & $\begin{array}{l}\text { Total no. of clinically } \\
\text { suspected cases }\end{array}$ & $\begin{array}{l}\text { No. (\%) of deaths } \\
\text { among suspected } \\
\text { cases } \ddagger\end{array}$ \\
\hline I (Initial) & 1969-1992 & $\begin{array}{c}1969-71(\mathrm{NC}, \mathrm{NE}) \\
1974(\mathrm{SE}, \mathrm{NW}) \\
1975 \text { and } 80(\mathrm{NC}, \mathrm{NW}) \\
1989(\mathrm{SE}, \mathrm{SS})\end{array}$ & $1.6(1-2)$ & 100 & $55(55.0)$ \\
\hline IIA (Transitional) & $1993-1997$ & $\begin{array}{c}1993 \text { (NC) } \\
1994 \text { (NE, SE, SS, SW) } \\
1995 \text { (NE, SE, SS) }\end{array}$ & $3.3(1-5)$ & 159 & $21(13.2)$ \\
\hline IIB (Transitional) & 1998-2008 & $\begin{array}{c}1998 \text { (SE, SS) } \\
1999(\mathrm{NW}) \\
2000 \text { (NC, SS) } \\
2001 \text { (SS) } \\
2002-2004(\mathrm{SS}, \mathrm{SW}) \\
2005 \text { (SE, SS, SW) } \\
2006 \text { (SS) } \\
2007 \text { (NC, SS) } \\
2008 \text { (NC, SE, SS, SW) }\end{array}$ & $2.1(1-7)$ & 844 & $325(38.5)$ \\
\hline III (Consolidation) & 2009-2020 & $\begin{array}{c}2009-2020 \text { (NC, SS, SW) } \\
2010-14,2016-20 \text { (SE) } \\
2009-20 \text { (NE) } \\
2009-12,2015-20 \text { (NW) } \\
2009,2011-12,2014-16,2019-20 \text { (FCT) }\end{array}$ & $19.8(9-35)$ & 26,908 & $1,443(5.4)$ \\
\hline Total & 1969-2020 & NA $\quad$ (NA) & NA & 28,011 & $1,844(6.6)$ \\
\hline
\end{tabular}

FCT = Federal Capital Territory; NA = Not applicable; NC = North Central; NE = Northeast; NW = Northwest; SE = Southeast; SS = South-South; SW = Southwest. Statistics I: $\chi^{2} /$ degrees of freedom $/ P$ are: $† 34.2 / 2 /<0.001$ (with IIA and B merged); 42.83/3/ $<0.001$ (without merging of IIA and B); $\ddagger 1,717 / 2 /<0.001$ (with IIA and B merged); $1,856 / 4 /<0.001$ (without merging of IIA and B). Statistics II: Extended Mantel-Haenszel $\chi^{2}$ for linear trend/ $P$ are: $† 24.95 /<0.001 ; \S 1,343.33 /<0.001$.

${ }^{*}$ I: Irregular annual outbreaks, with shifts between northern and southern Nigeria with high CFR; IIA: Irregular annual outbreaks involving both northern and southern Nigeria; IIB: Regular annual outbreaks involving predominantly southern but also occasionally northern Nigeria with high CFR; III: Regular annual national outbreaks consistently involving $\geq 7 / 36$ states in $\geq 4 / 6$ geopolitical zones in the country.

et al., ${ }^{47}$ and Mazzola and Kelly-Cirino, ${ }^{48}$ among others, have recently reviewed the various techniques, including those available in resource-limited settings, and the polymerase chain reaction $(\mathrm{PCR})$ test is currently acclaimed the most specific and sensitive. ${ }^{45-50}$ However, the difficulties in diagnosis have been longstanding, ${ }^{17,51}$ and testing capacity has remained limited in LF endemic areas because of equipment expense and paucity of adequately trained laboratory personnel.

About 22 years ago, one of us (D. E. A.) lamenting the dearth of diagnostic laboratories in the country had wondered, "How can we cope as a nation, if we are suddenly confronted by the emergence of a new deadly super virus?"52 The increasing waves of LF outbreaks in the country, and the advent of other highly infectious diseases including COVID-19 $9^{53}$ have increased the urgent need for more molecular diagnostic facilities in Nigeria. Asogun et al. ${ }^{45}$ have reported on the success of the pioneering efforts to develop LF diagnostic capacity in Nigeria, and by the end of 2019 about seven molecular diagnostic facilities were now in place. Although this was a considerable improvement on the situation before $2008,{ }^{51}$ the number remains grossly inadequate for a country with an estimated population of about 200 million, and some of the facilities are understandably being overstretched. ${ }^{17,54} \mathrm{We}$ note, however, that Nigeria in response to the COVID-19 pandemic has established about 70 new molecular diagnostic facilities. This is a welcome development, and it is hoped that some of these facilities could be deployed for the diagnosis of other infectious diseases including LF, post COVID-19. The establishment of more diagnostic centers is a major milestone in the ongoing LF control efforts, and it is important to acknowledge the role of development partners, particularly the European Union, in this regard. We also wish to acknowledge the gains in LF surveillance and response since the coming of the current leadership of NCDC in 2015.

TABLE 5

Population incidence and case fatality of Lassa fever during three time periods, 1969-1992 vs. 1993-2008 vs. 2009-2020

\begin{tabular}{|c|c|c|c|c|c|}
\hline \multicolumn{2}{|c|}{ Outbreak period } & \multirow[b]{2}{*}{$\begin{array}{l}\text { Average population of } \\
\text { Nigeria during the period }\end{array}$} & \multicolumn{2}{|c|}{ No. of cases per million of the population } & \multirow[b]{2}{*}{$\begin{array}{l}\text { Case fatality among } \\
\text { suspected cases (\%) }\end{array}$} \\
\hline Years & $\begin{array}{l}\text { Phase (No. of confirmed/ } \\
\text { suspected cases of LF) }\end{array}$ & & Suspected cases & Confirmed cases & \\
\hline 1969-1992 & I (54/100) & $75,235,133.75$ & 1.329 & 0.718 & $55 / 100(55.0)$ \\
\hline 1993-2008 & II (303/1003) & $124,822,313.5$ & 8.035 & 2.428 & $346 / 1003(34.5)$ \\
\hline 2009-2020 & III $(3,797 / 26,908)$ & $179,331,799.6$ & 150.046 & 21.173 & $1,443 / 26,908(5.14)$ \\
\hline \multicolumn{6}{|l|}{ Statistics } \\
\hline \multicolumn{3}{|c|}{ Extended Mantel-Haenszel $\chi^{2}$ for linear trend; $P$ value } & $21,865.3 ;<0.001$ & $2,737.55 ;<0.001$ & $1,812.29 ;<0.001$ \\
\hline \multicolumn{3}{|c|}{ OR $(95 \% \mathrm{Cl})$ phase I vs. II } & $0.17(0.14,0.20)$ & $0.30(0.22,0.40)$ & $2.32(1.53,3.51)$ \\
\hline \multicolumn{3}{|c|}{ OR (95\% Cl) phase I vs. III } & $0.009(0.007,0.011)$ & $0.034(0.026,0.044)$ & $21.57(14.49,32.1)$ \\
\hline \multicolumn{3}{|c|}{ OR $(95 \% \mathrm{Cl})$ phase II vs. III } & $0.054(0.050,0.057)$ & $0.115(0.102,0.129)$ & $9.30(8.08,10.7)$ \\
\hline
\end{tabular}




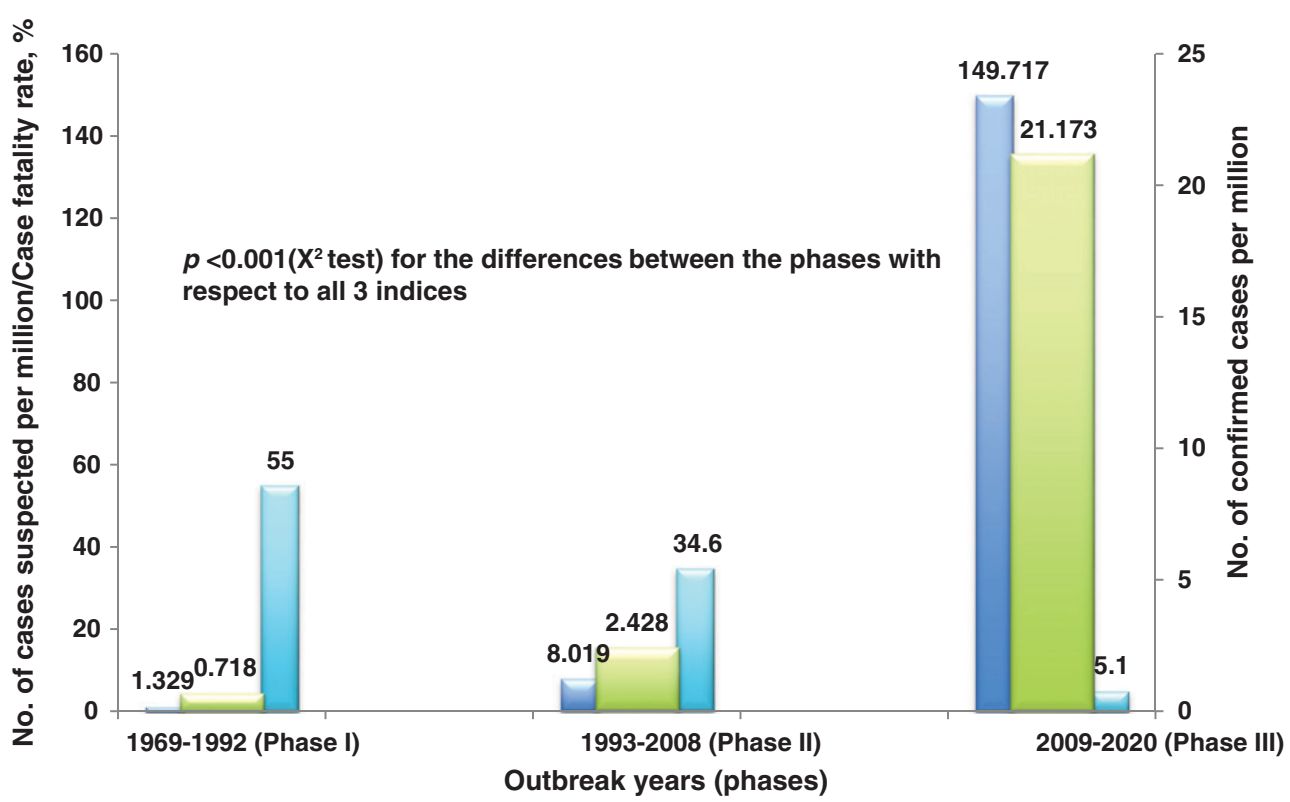

\section{$\square$ Population incidence of suspected cases \\ $\square$ Case fatality among suspected cases, $\%$}

$\square$ Population incidence of confirmed cases

FIGURE 6. Population incidence of suspected and confirmed cases, and case fatality among suspected cases of Lassa fever, 1969-1992 vs. 1993-2008 vs. 2009-2020. This figure appears in color at www.ajtmh.org.

Besides the dearth of molecular diagnostic facilities is the problem posed by genetic variation among LASV strains. ${ }^{55}$ The LASV lineages in Nigeria are more diverse than in other West African countries, ${ }^{56}$ and this has limited the efforts at developing a universal LASV-specific real-time reverse transcription (RT)-PCR assay and rapid diagnostic tests. However, the current protocol for LASV-RT-PCR in Nigeria is expected to pick up at least $99 \%$ of the circulating LASV strains. $^{33,57}$

Second, could be factors related to the transmission of infection: increased incidence of bush burnings, increased farming activities, and improper storage of food items; ${ }^{13,17,58-61}$ climate change/global warming with increased occurrence of natural disasters including flooding; ${ }^{62}$ population pressures, and increasing poverty levels; ${ }^{17}$ and unwholesome cultural practices. The latter include hunting of the rodent vectors for meat, burial practices, and sun drying of Garri (grains of Manihort esculensis) on the ground in rural areas, which exposes the popular carbohydrate source to contamination with the urine and droppings of the vector rats. There is also the propagation of nosocomial transmission by the poor standards of medical practice in some healthcare settings. ${ }^{11,63}$ Further studies are required to determine the relative contribution of the various methods of transmission to the spread of LF in Nigeria. Meanwhile, the finding that recent increases in LF cases are because of increased rodent-to-human transmissions rather than LASV strain variation $^{57,61}$ underscore the importance of rodent control and prevention of man-rodent contact. It also highlights the need for more studies on the density and distribution of infected rodents in the country.

Third, are the erstwhile poor national and international responses, ${ }^{5}$ which indeed border on negligence. Reviewing the national response in a keynote address during the first subregional conference on LF in 2007, one of us (O. T.) stated that: "Talking about the last 38 years of Lassa fever in Nigeria, is talking of the tragedy of a nation. The story of Lassa fever in Nigeria is the story of criminal apathy and vicious ignorance." 51 However, we note with encouragement that Nigeria is now rising to the challenge, a development that is partly signposted by the hosting in recent years of several international conferences and workshops on LF control. ${ }^{31,51,66}$

Lastly, it is important to note the consistency of LF outbreaks in Edo State, ${ }^{17,37,39,40,67,68}$ and the notable increases of cases in that state as well as Plateau, Ondo, and Ebonyi States in particular, and Nigeria in general, within the past 6 years, 2015-2020. ${ }^{17,54}$ Besides the factors described earlier (vide supra) these surges could also be because of improved case recognition by clinicians and increased patronage of health facilities as a result of increased public awareness, and availability of laboratory diagnostics and therapy. Nonetheless, we think that the dramatic surges in numbers of affected states and cases that began about 2009 and have continued since then may be more than coincidental with the availability of in-country diagnostic capability in $2008 .{ }^{17}$ This view is supported by recent reports of increased rodent-to-human transmission of infections. ${ }^{54,57,61}$ The spread of LF outbreaks in Nigeria well beyond the zones predicted previously ${ }^{58}$ confirms the observation of Sogoba et al. ${ }^{69}$ of an expanded area of LF endemicity in West Africa.

The increasing caseload, especially since 2005, contrasts strongly with the decreasing case fatality. The latter is reassuring to an extent, and may be because of improvements in diagnosis and case management, ${ }^{14,17}$, including the greater availability of ribavirin, ${ }^{17}$ not minding recent questions regarding its effectiveness. ${ }^{70}$ The recent surges in 
caseload, ${ }^{17,40,54,64,71-74}$ underline the need for a greater sense of urgency in the sourcing and implementation of more effective countermeasures.

Measures to stem the course of Lassa fever outbreaks? We are now in the sixth decade since the first reports of the outbreaks, which are rightly dreaded both by healthcare workers $^{30}$ and the public, ${ }^{65,75-77}$ and the success control efforts in Nigeria could transcend the country. The requirements for its control have been the subject of extensive deliberations, ${ }^{31,51,66,78,79}$ and the foresighted and farsighted recommendations therefrom encapsulate the prerequisites for success in mitigation of the outbreaks. We wish to humbly refer our readers to the published outputs from the meetings. Nevertheless, we must point out the place of development of diagnostic capacity and enhanced surveillance, clinical case management and the protection of healthcare workers (HCWs), rodent control, and research from among the many recommendations.

Adequate clinical case management is fundamental to the reduction of mortality among critically ill patients, ${ }^{14,17,80,81}$ and thus also to reduction of the fear, hopelessness, and stigmatization often attached to LF. ${ }^{82}$ This requires that the many issues that could contribute to better clinical care and improved outcomes are addressed. ${ }^{17}$ We should develop tiered referral systems with increasing levels or complexity of care, in which the apex referral centers are adequately equipped and staffed to provide dedicated critical care for severely ill patients with LF/other viral hemorrhagic fevers. ${ }^{17,80,83,84}$ Only a few of such centers are available presently, ${ }^{17,54}$ but the increasing prevalence of severe VHFs including LF, Ebola, and Yellow fever, and other emerging infectious diseases (EIDS) such as COVID-19, makes the development of more centers urgent. Reviews such as ours that comprehensively chronicle the outbreaks and objectively detail the distribution of the burden of infection in the country could be a useful guide to policy and mitigation efforts.

The training and retraining of HCWs on IPC measures ${ }^{85-87}$ including the use of personal protective equipment (PPEs), ${ }^{17}$ coupled with adequate monitoring of adherence to the standard practices, could almost eradicate nosocomial transmission in healthcare facilities. Given recent findings on the contribution of rats to the transmission of $L F,{ }^{57,61}$ rodent control should be strengthened to complement other countermeasures within the framework of "One Health." 88 Citizens must be discouraged from hunting and eating rodents, while the population of rats is reduced through conscious efforts, including trapping and the use of rodenticieds. ${ }^{89,90}$ Biological control, haven shown great promise in the control of malaria and dengue fever, ${ }^{91}$ could also be a viable option. However, it should be borne in mind that the wide distribution of rodents in the woody transitional Savannah and forest zones of West Africa could make "complete control" of rodent reservoirs impractical. ${ }^{92,93}$

The development of effective vaccines is imperative as a public health need, and is one of the thematic areas of focus in the WHO's Strategic Roadmap for LF Control. ${ }^{79}$ Several authors ${ }^{94,95}$ have recently reviewed the progress made, and calls for proposals are already out for the clinical trial of some products. However, schemes to ensure equitable access by populations in endemic areas, and question of prioritization of $\mathrm{HCW}$ s versus the general public would need to be worked out.
It is thus important to discuss the funding mechanisms on time.

Finally, we note that research is critical to the control of LF. ${ }^{79}$ The research needs have been extensively reviewed by several authors. ${ }^{79,81,96-99}$ Among the needs, we think that the development of rapid diagnostic tests, therapeutic alternatives or complements to ribavirin, mapping of infected rodents, and the setting of minimum benchmarks for the use of PPE, should be prioritized for action in the short term.

Limitations of the study. During the first many years of the outbreaks, affected communities viewed the disease with fear, suspicion, and disbelief. The "strange deaths" were generally ascribed to "witchcraft," 68,100 and investigators were afraid to go near the communities. These fears were real and have been vividly captured in "MY FATHERS \& I."100 from representative situations during the 1989 outbreaks. Under these circumstances, it is conceivable that there might have been a large number of unreported cases, particularly during the earlier phases of the outbreaks. This would be more so given the low state of public awareness, generally low index of suspicion among physicians and paucity of diagnostic facilities at that time, particularly between 1969 and 2008 when blood specimens from suspected cases had to be sent overseas for confirmatory testing. ${ }^{17}$ However, about $7.1-29.8 \%$ of the clinically suspected cases seen between 2008 and 2018 in one center were confirmed, ${ }^{17}$ and the rates in this review are mostly within this range. Therefore, we believe that these limitations should not detract from the lessons from our review.

\section{CONCLUSION}

Within the past 52 years, Nigeria has been plagued with recurrent outbreaks of LF, which have grown from irregular to regular annual, and from limited local to nationwide outbreaks. This appears to be principally as a result of inadequate government attention and perhaps the poor coordination of risk communication strategies. Although the attitudinal disposition has markedly improved over the last few years, the omissions of the past continue to impact on the present in the form of increasing magnitude of outbreaks. Pending the availability of effective vaccines, much work may be required to dampen the surge in case numbers and sustain the decreases in case fatality.

Received September 8, 2020. Accepted for publication June 29, 2021.

Published online August 30, 2021.

Note: Supplemental table appears at www.ajtmh.org.

Acknowledgments: We wish to acknowledge the fortitude of the numerous persons, families, and communities that have over the years borne the burden of Lassa fever. We also wish to acknowledge the dedication of the numerous scientists and healthcare workers, some of whom have lost their lives in the course of duty, involved in Lassa fever research and clinical care. Furthermore, we acknowledge the many individuals, institutions, nongovernmental and governmental organizations, agencies, and governments, at subnational, national, subregional, regional, and international levels, which have contributed in different ways to Lassa fever research and clinical care activities. The American Society of Tropical Medicine and Hygiene (ASTMH) assisted with publication expenses.

Authors' addresses: Dennis E. Agbonlahor, Department of Medical Laboratory Science, College of Medical Sciences, Edo State University, Uzairue, Edo State, Nigeria, and Lahor Research Laboratories and 
Medical Centre, Benin City, Edo State, Nigeria, E-mail: deagonlahor@ yahoo.com. George O. Akpede, Department of Paediatrics, College of Medicine, Ambrose Alli University, Ekpoma, Edo State, Nigeria, and Institute of Lassa Fever Research and Control, Irrua Specialist Teaching Hospital, Irrua, Edo State, Nigeria, E-mail: georgeakpede@ yahoo.co.uk. Christian T. Happi, Department of Biological Sciences, Redeemer's University, Ogun State, Nigeria and African Center of Excellence for Genomics of Infectious Diseases (ACEGID), Redeemer's University, Ogun State, Nigeria, E-mail: happi@run.edu. ng. Oyewale Tomori, Redeemer's University, Ede, Osun State, Nigeria, and National Laboratory Technical Working Group, Federal Ministry of Health, Abuja, Nigeria, E-mail: oyewaletomori@yahoo.com.

\section{REFERENCES}

1. Troup JM, White HA, Fom AL, Carey DE, 1970. An outbreaks of Lassa fever on the Jos Plateau, Nigeria, in January-February 1970. Am J Trop Med Hyg 19: 695-696.

2. Frame JD, Baldwin JM Jr, Gocke DJ, Troup JM, 1970. Lassa fever, a new virus disease of man from West Africa I. Clinical description and pathological findings. Am J Trop Med Hyg 19: 670-676.

3. Leifer E, Gocke DJ, Bourne H, 1970. Lassa fever, a new virus disease of man from West Africa II. Report of a laboratoryacquired infection treated with plasma from a person recently recovered from the disease. Am J Trop Med Hyg 19: 677-679.

4. Buckley SM, Casals J, 1970. Lassa fever, a new virus disease of man from West Africa III. Isolation and characterization of the virus. Am J Trop Med Hyg 19: 680-691.

5. Akpede GO, Asogun DA, Okogbenin SA, Okokhere PO, 2018. Lassa fever outbreaks in Nigeria. Expert Rev Anti Infect Ther 16: 663-666.

6. Monath TP et al., 1974. Lassa fever in the eastern province of Sierra Leone, 1970-1972 II. Clinical observations and virological studies on selected hospital cases. Am J Trop Med Hyg 23: 1140-1149.

7. Agbonlahor DE et al., 2017. Prevalence of Lassa virus among rodents trapped in some South-South States of Nigeria. J Vect Borne Dis 54: 146-150. Available at: http://www.jvbd.org/text. asp?2017/54/2/146/211689.

8. Carey DE et al., 1972. Lassa fever. Epidemiological aspects of the 1970 epidemic, Jos, Nigeria. Trans R Soc Trop Med Hyg 66: 402-408.

9. Keenlyside RA, McCormick JB, Webb PA, Smith E, Elliott L, Johnson KM, 1983. Case-control study of Mastomys natalensis and humans in Lassa virus-infected households in Sierra Leone. Am J Trop Med Hyg 32: 829-837.

10. McCormick JB et al., 1987. A case-control study of the clinical diagnosis and course of Lassa fever. J Infect Dis 155: 445-455.

11. Fisher-Hoch SP et al., 1995. Review of cases of nosocomial Lassa fever in Nigeria: the high price of poor medical practice. BMJ 311: 857-859.

12. Center for Disease Control, 2004. Lassa Fever Fact Sheet. Atlanta, GA: US Department of Health and Human Services, CDC. Available at: http://www.cdc.gov/ncidod/dvrd/spb/ mnpages/dispages/lassaf.htm.

13. Richmond JK, Baglole DJ, 2003. Lassa fever: epidemiology, clinical features, and social consequences. BMJ 327: 12711275.

14. Okokhere $P$ et al., 2018. Clinical and laboratory predictors of Lassa fever outcome in a dedicated treatment facility in Nigeria: a retrospective, observational cohort study. Lancet Infect Dis 18: 684-695.

15. Ogbu O, Ajuluchukwu E, Uneke CJ, 2007. Lassa fever in West African sub region: an overview. J Vector Borne Dis 44: 1-11.

16. Asogun DA, Gunther S, Akpede GO, Ihekweazu C, Zumla A, 2019. Lassa fever: epidemiology, clinical features, diagnosis, management and prevention. Infect Dis Clin North Am 33: 933951.

17. Akpede GO et al., 2019. Caseload and case fatality of Lassa fever in Nigeria, 2001-2018: a specialist center's experience and its implications. Front Public Health 7: 170.

18. Cummins $D$ et al., 1990. Acute sensorineural deafness in Lassa fever. JAMA 264: 2093-2096.
19. Ibekwe TS et al., 2011. Early-onset sensorineutral hearing loss in Lassa fever. Eur Arch Otorhinolaryngol 268: 197-201.

20. Mateer EJ, Huang C, Shehu NY, Paessler S, 2018. Lassa feverinduced sensorineural hearing loss: a neglected public health and social burden. PLoS Negl Trop Dis 12: e0006187.

21. Price ME, Fisher-Hoch SP, Craven RB, McCormick JB, 1988. A prospective study of maternal and fetal outcome in acute Lassa fever infection during pregnancy. BMJ 297: 584-587.

22. Dahmane A et al., 2014. Constraints in the diagnosis and treatment of Lassa fever and the effect on mortality in hospitalized children and women with obstetric conditions in a rural district hospital in Sierra Leone. Trans $R$ Soc Trop Med Hyg 108: 126-132.

23. Okogbenin S et al., 2019. Retrospective cohort study of Lassa fever in pregnancy, southern Nigeria. Emerg Infect Dis 25: 1494-1500.

24. Kayem ND et al., 2020. Lassa fever in pregnancy: a systematic review and meta-analysis. Trans $R$ Soc Trop Med Hyg 114: 385-396.

25. Webb PA et al., 1986. Lassa fever in children in Sierra Leone, West Africa. Trans R Soc Trop Med Hyg 80: 577-582.

26. Akhuemokhan OC et al., 2017. Prevalence of Lassa Virus Disease (LVD) in Nigerian children fever or fever and convulsions in an endemic area. PLoS Negl Trop Dis 11: e0005711.

27. Akpede GO et al., 2019. Acute abdomen in pediatric patients with Lassa fever: prevalence and response to non operative management. J Pediatric Infect Dis Soc 8: 519-524.

28. Frame JD, 1989. Clinical features of Lassa fever in Liberia. Rev Infect Dis 11: S783-S789.

29. Omilabu SA et al., 2005. Lassa fever, Nigeria, 2003-2004. Emerg Infect Dis 11: 1642-1644.

30. Mustapha A, 2017. Lassa fever: unveiling the misery of the Nigerian health worker. Ann Niger Med 11: 1-5.

31. Nigeria Centre for Disease Control, 2019. Lassa Fever at 50: Rising to the Challenge. Lassa Fever International Conference, January 16-17, 2019, Transcorp Hilton, Abuja, Nigeria.

32. Emperador DM, Yimer SA, Mazzola LT, Norheim G, Kelly-Cirino C, 2019. Diagnostic applications for Lassa fever in limitedresource settings. BMJ Glob Health 4 (Supp/ 2): e001119.

33. Nigeria Centre for Disease Control, 2018. National Guidelines for Lassa Fever Case Management. Available at: www.ncdc. gov.ng.

34. White HA, 1972. Lassa fever: a study of 23 hospital cases. Trans $R$ Soc Trop Med Hyg 66: 390-401.

35. Bowen GS, Tomori O, Wulf H, Casals J, 1974. Lassa fever in Onitsha, East Central State, Nigeria, in 1974. Bull World Health Org 52: 599-604.

36. Holmes GP et al., 1990. Lassa fever in the United States: investigation of a case and new guidelines for management. N Engl J Med 323: 1120-1123.

37. Ogoina D, Pondei K, Adetunji B, Chima G, Isichei C, Gidado S, 2015. Knowledge, attitude and practice of standard precautions of infection control by hospital workers in two tertiary hospitals in Nigeria. J Infect Prev 16: 16-22.

38. Ogoina D, 2013. Lassa fever: a clinical and epidemiological review. Nig Delta J Med Med Res 1: 1-10.

39. Akpede $\mathrm{G}$ et al., 2010. Spatial and temporal trends of the Lassa fever epidemic in Nigeria 2001-2009, with particular reference to the Edo State experience. Int J Infect Dis 14: e476-e477.

40. Ajayi AA et al., 2013. Containing a Lassa fever epidemic in a resource-limited setting: outbreak description and lessons learned from Abakaliki, Nigeria (January-March 2012). Int J Infect Dis 17: 1011-1016.

41. Ajogbasile FV et al., 2020. Real-time metagenomic analysis of undiagnosed fever cases unveils a yellow fever outbreak in Edo State, Nigeria. Sci Rep 10: 3180.

42. Okokhere PO, Asogun DA, Dawodu SO, Omilabu SA, Akpede $\mathrm{GO}, 2013$. Clinical presentation and constraints in the diagnosis of Lassa fever in Nigeria. Ambrose Alli Univ Postgrad J 1: 50-62.

43. Olowookere SA, Fatiregun AA, Gbolahan OO, Adepoju EG, 2014. Diagnostic proficiency and reporting of Lassa fever by physicians in Osun State of Nigeria. BMC Infect Dis 14: 344.

44. Dhillon RS, Srikrishna D, Garry RF, 2018. Early detection of Lassa fever: the need for point-of-care diagnostics. Lancet Infect Dis 18: 601-602. 
45. Asogun DA et al., 2012. Molecular diagnostics for Lassa fever at Irrua specialist teaching hospital, Nigeria: lessons learnt from two years of laboratory operation. PLoS Negl Trop Dis 6: e1839.

46. Raabe V, Koehler J, 2017. Laboratory diagnosis of Lassa fever. $J$ Clin Microbiol 55: 1629-1637.

47. Takah N, Branget P, Shrastha P, Peeling R, 2019. Sensitivity and specificity of diagnostic tests for Lassa fever: a systematic review. BMC Infect Dis 19: 647.

48. Mazzola LT, Kelly-Cirino C, 2019. Diagnostics for Lassa fever virus: a genetically diverse pathogen found in low resource settings. BMJ Glob Health 4: e001116.

49. Bausch DG et al., 2000. Diagnosis and clinical virology of Lassa fever as evaluated by enzyme-linked immuno- sorbent assay, indirect fluorescent-antibody test, and virus isolation. J Clin Microbiol 38: 2670-2677.

50. Gunther S, Lenz O, 2004. Lassa virus. Crit Rev Clin Lab Sci 41: 339-390.

51. Akpede GO, Coker ABE, Oboh TA, Agbai CV, 2007. Preliminary Report of the First Regional Conference on Lassa Fever. December 5-8, 2007, Reiz Continental Hotel, Central Business District, Abuja, Nigeria.

52. Agbonlahor DE, 1998. Mankind exploited, microbes revolted and their Maker intervened. Ambrose Alli Inaugural Lecture, Series No. 9, Delivered at Edo State University, April 22, 1998, Ekpoma, Nigeria.

53. Amzata J, Aminub K, Kolob VI, Akinyele AA, Ogundairob JA, Danjibob MC, 2020. Coronavirus outbreak in Nigeria: burden and socio-medical response during the first 100 days. Int $J$ Infect Dis 98: 218-224.

54. Ilori EA et al., 2019. Increase in Lassa fever cases in Nigeria, January-March 2018. Emerg Infect Dis 25: 1026-1027.

55. Bowen MD et al., 2000. Genetic diversity among Lassa virus strains. J Virol 74: 6992-7004.

56. Ehichioya DU et al., 2012. Hospital surveillance for Lassa fever in Edo State, Nigeria, 2015-2008. Trop Med Int Health 17: 10011004.

57. Siddle KJ et al., 2018. Genomic analysis of Lassa virus during an increase in cases in Nigeria in 2018. N Engl $J$ Med 379: 17451753.

58. Fichet-Calvet E, Rogers DJ, 2009. Risk maps of Lassa fever in West Africa. PLoS Negl Trop Dis 3: e388.

59. Monath TP, 1975. Lassa fever: review of epidemiology and epizootiology. Bull World Health Organ 52: 577-592.

60. Lecompte E, Fichet-Calvet E, 2006. Mastomys natalensis and Lassa fever, West Africa. Emerg Infect Dis 12: 1971-1974.

61. Kafetzopoulou LE et al., 2019. Metagenomic sequencing at the epicenter of the Nigeria's 2018 Lassa fever outbreak. Science 363: 74-77.

62. Akhmetzhanov AR, Asai Y, Nishiura H, 2019. Quantifying the seasonal drivers of transmission for Lassa fever in Nigeria. Philos Trans R Soc Lond B Biol Sci 374: 20180268.

63. Frame JD, 1975. Surveillance of Lassa fever in missionaries stationed in West Africa. Bull World Health Organ 52: 593-598.

64. Saka JM, Gubic AB, Kerecvel YS, Saka AO, 2017. Lassa fever epidemic in Nigeria-outbreak investigation, risk factors and empirical analysis from 2012 to 2016. J Com Publ Health Nurs 3: $1-6$.

65. Editorial, 2020. Five Years of Annual Lassa Fever Occurrence! February 6, 2020. Available at: https://guardian.ng/opinion/fiveyears-of-annual-lassa-fever-occurrence/. Accessed August 13, 2020.

66. Federal Ministry of Health, Nigeria, Edo State Government, Nigeria, Irrua Specialist Teaching Hospital, Nigeria, Bernhard Nocht Institute of Tropical Medicine, Germany, European Union Mobile Laboratory Consortium. West African sub-regional workshop on epidemic preparedness and response to Lassa fever and other HIDs in the sub-region. February 16-21, 2014, Western Homeville Hotel, Benin City, Nigeria.

67. Ehichioya DU et al., 2010. Lassa fever, Nigeria, 2005-2008. Emerg Infect Dis 16: 1040-1041.

68. Agbonlahor DE, 1991. On the socio-politics and mysticisms of Lassa fever outbreaks in Nigeria. J Med Lab Sci 1: 1-7.

69. Sogoba N, Feldmann H, Safronetz D, 2012. Lassa fever in West Africa: evidence for an expanded region of endemicity. Zoon Publ Health 59: 43-47.
70. Eberhardt KA, Mischlinger J, Jordan S, Groger M, Günther S, Ramharter M, 2019. Ribavirin for the treatment of Lassa fever: a systematic review and meta-analysis. Int $\mathrm{J}$ Infect Dis 87: 15-20.

71. Nigeria Centre for Disease Control (NCDC). Lassa Fever Outbreak Situation Report, 51 Weeks. December 31, 2017. Available at: www.ncdc.gov.ng.

72. Nigeria Centre for Disease Control (NCDC). Lassa Fever Outbreak Situation Report, 52 Weeks. December 31, 2018. Available at: www.ncdc.gov.ng.

73. Nigeria Centre for Disease Control (NCDC). Lassa Fever Outbreak Situation Report, 19 Weeks. May 12, 2019. Nigeria Centre for Disease Control (NCDC). Lassa Fever Outbreak Situation Report, 26 Weeks. June 30, 2019. Available at: www.ncdc.gov. ng.

74. Nigeria Centre for Disease Control (NCDC). Weekly Epidemiology Report. Weekly Updates on Epidemics in Nigeria: As at October 31, 2016. Vol. 6, No 41. Available at: www.ncdc.gov. ng.

75. Editorial, 2013. Curbing resurgent Lassa fever menace. Sunday Punch March 3, 2013. 16.

76. Editorial, 2009. Lassa fever and official negligence. Sunday Punch March 8, 2009. 16.

77. Editorial, 2018. Resurgence of Lassa fever in Nigeria. January 28 , 2018. Available at: https://guardian.ng/opinion/resurgence-oflassa-fever-in-nigeria/. Accessed August 13, 2020.

78. World Health Organization, and the Governments of Cote D'Ivoire, Ghana, Guinea, Liberia, Mali, Nigeria and Sierra Leone Ministries of Health, 2011. Five year strategic plan for the prevention and control of Lassa fever and severe emerging infectious diseases in the West African Sub-Region, 2012-2017. Workshop on the Control of Lassa fever and other Viral Haemorrhagic Fevers, held in Freetown, Sierra Leone, 2010.

79. World Health Organization, 2018. Lassa Fever Research and Development (R\&D) Roadmap. 2018. 1-18. Available at: https:// www.who.int/blueprint/priority-diseases/key-action/ LassaFever

80. Ippolito $\mathrm{G}$ et al., 2012. Viral hemorrhagic fevers: advancing the level of treatment. BMC Med 10: 31

81. Fischer WA II, Wohl DA, 2017. Moving Lassa fever research and care into the 21st century. J Infect Dis 215: 1779-1781.

82. Usifoh SF, Odigie AE, Ighedosa SU, Uwagie-Ero EA, Aighewi IT, 2019. Lassa fever-associated stigmatization among staff and students of the University of Benin, Nigeria. J Epidemiol Glob Health 9: 107-115.

83. Fowler RA et al., 2014. Caring for critically ill patients with Ebola virus disease-perspectives from West Africa. Am J Respir Crit Care Med 190: 733-737.

84. West TE, von Saint André-von Arnim A, 2014. Clinical presentation and management of severe Ebola virus disease. Ann Am Thorac Soc 11: 1341-1350.

85. Fisher-Hoch SP et al., 1985. Safe intensive-care of a severe case of Lassa fever with simple barrier nursing techniques. Lancet 2: 1227-1229.

86. Helmick CG, Webb PA, Scribner CL, Krebs JW, McCormick JB, 1986. No evidence for increased risk of Lassa fever infection in hospital staff. Lancet 2: 1202-1205.

87. Lehmann $\mathrm{C}$ et al., 2017. Control measures following a case of imported Lassa fever from Togo, North Rhine Westphalia, Germany, 2016. Euro Surveill 22: 17-0008.

88. Tambo E, Adetunde OT, Olalubi OA, 2018. Re-emerging Lassa fever outbreaks in Nigeria: Re-enforcing 'One Health' community surveillance and emergency response practice. Infect Dis Poverty 7: 37.

89. Ogundipe S, 2009. Fall out of Lassa fever outbreak: W.A.R. [War against rats] in Lagos over Lassa fever. Sunday Vanguard, March 21, 2009. 11-12.

90. Saez AM, Haidara MC, Camara A, Kourouma F, Sage MI, Magassouba N'F, Fichet-Calvet E, 2018. Rodent control to fight Lassa fever: evaluation and lessons learned from a 4-year study in Upper Guinea. PLoS Negl Trop Dis 12: e0006829.

91. Rawal D, 2019. A review on different strategies used for biological control of mosquitoes. Int J Mosq Res 6: 41-43.

92. Keenlyside RA, McCormick JB, Webb PA, Smith E, Elliott L, Johnson KM, 1983. Case control study of Mastomys natalensis 
and humans in Lassa virus-infected households in Sierra Leone. Am J Trop Med Hyg 32: 829-837.

93. Granjon L, Du Plantier JM, Catalan J, Britton-Davidian J, 1997. Systematics of the genus Mastomys. Belg J Zool 127: 7-18.

94. Lukashevich IS, Paessler S, de la Torre JC, 2019. Lassa virus diversity and feasibility for universal prophylactic vaccine. F1000Res 8: 134.

95. Purushotham J, Lambe T, Gilbert SC, 2019. Vaccine platforms for the prevention of Lassa fever. Immunol Lett 215: 1-11.

96. Khan SH et al., 2008. New opportunities for field research on the pathogenesis and treatment of Lassa fever. Antiviral Res 78: 103-115.

97. Kerber R et al., 2014. Research efforts to control highly pathogenic arenaviruses: a summary of the progress and gaps. J Clin Virol 64: 120-127.
98. Sigfrid $L$ et al., 2019. A rapid research needs appraisal methodology to identify evidence gaps to inform clinical research priorities in response to outbreaks-results from the Lassa fever pilot. BMC Med 17: 107.

99. Garnett LE, Strong JE, 2019. Lassa fever: with 50 years of study, hundreds of thousands of patients and an extremely high disease burden, what have we learned? Curr Opin Virol 37: 123-131.

100. Tomori O, 2010. Some special tributes, p. 212. In: Agbonlahor DE. My Fathers \& I-A Biotrip of Divinations. Cromwell \& Clinton Ltd, Lagos, Nigeria for Dennike Media Company, 121 Old Benin-Agbor Road, Ohovbe-ogbeson Quarters, Benin City, Edo State, Nigeria. 